\title{
Water perturbed by cellophane: comparison of its physicochemical properties with those of water perturbed with cotton wool or Nafion
}

\author{
Vittorio Elia ${ }^{1}$ Elena Napoli ${ }^{1} \cdot$ Roberto Germano $^{2,3}$ (1) $\cdot$ Valentina Roviello ${ }^{4} \cdot$ Rosario Oliva $^{1} \cdot$ Marcella Niccoli $^{1}$. \\ Angela Amoresano ${ }^{1} \cdot$ Maria Toscanesi $^{5} \cdot$ Marco Trifuoggi $^{5}$. Antonio Fabozzi ${ }^{1} \cdot$ Tamar A. Yinnon $^{6,7}$
}

Received: 4 June 2019 / Accepted: 12 August 2020 / Published online: 4 September 2020

(c) The Author(s) 2020

\begin{abstract}
We present experimental data on water repetitively brought in contact with cellophane. Although this hydrophilic polymer is insoluble in water, repetitively immersing it in water changes the liquid's properties. We compare the physicochemical properties of the water left over after removing the cellophane to those of previously published data on water repetitively brought in contact with other in water insoluble polymers (cotton wool or Nafion). Some of the properties are similar. All the properties considerably differ from those of the Milli- $\mathrm{Q}^{\circledR}$ water used. On lyophilizing these waters, solid residues remain. The residues are soluble in water. The chemical nature of the residues differs from that of the perturbing polymers.
\end{abstract}

Keywords Water $\cdot$ Cellophane $\cdot$ Cellulose $\cdot$ Mirror symmetry $\cdot$ Interfacial water $\cdot$ Nafion

\section{Introduction}

Customarily, it is assumed that natural or artificial cellulose polymers do not affect nearby bulk water. The insolubility of cellulose in water underlies this assumption [1]. Nevertheless, the recently well-checked experiments that we

Electronic supplementary material The online version of this article (https://doi.org/10.1007/s10973-020-10185-0) contains supplementary material, which is available to authorized users.

Roberto Germano

germano@promete.it

1 Department of Chemical Sciences, University "Federico II", Complesso Universitario di Monte Sant'Angelo, Via Cintia, 80126 Naples, Italy

2 PROMETE Srl, CNR Spin Off, P.le V. Tecchio, 45, 80125 Naples, Italy

3 University "Federico II", Complesso Universitario di Monte Sant'Angelo, Via Cintia, 80126 Naples, Italy

4 Advanced Metrologic Service Center (CeSMA), University of Naples Federico II, Corso Nicolangelo Protopisani, 80146 Naples, Italy

5 Chemical Science Department, Analytical Chemistry for Environment Institute, "Federico II" University of Napoli, Naples, Italy

6 K. Kalia, D.N. Kikar Jordan, 90666 Kalia, Israel

7 Reedmace Lake, Enot Tsukim Nature Reserve, Kalia, Israel performed have upturned this assumption [2-4]. We perturbed Milli-Q water by bringing it repetitively in contact with hydrophilic cellulose (HC) (cotton wool), cellulose acetate or cellulose nitrate polymers. The physicochemical properties of the water left over removing the polymers differ from those of Milli- $Q^{\circledR}$ water. For example, the perturbed water is an optical active, far-out-of equilibrium self-organizing system. It contains molecular associates with sizes reaching hundreds of nano-meters $(\mathrm{nm}) .{ }^{1}$ The values of the physicochemical variables of water perturbed with a cellulose polymer are correlated [2-4]. The correlations indicate that a single cause underlies its peculiar phenomena. For example, the linear correlation between the logarithms $(\log )$ of electrical conductivity $(\chi)$ and density of the perturbed water reflects the liquid's scale-free self-similar fractal properties [2,5].

The modifications in the properties of liquid water induced by its repeated interaction with cellulose are not ascribable to chemical impurities (compounds of the polymers, organic or biological impurities), as the cutting-edge analytical measurements demonstrate [2-4]. Instead, it is our conjecture that on immersing $\mathrm{HC}$ in water and subsequently

\footnotetext{
${ }^{1}$ Our experiments show that the following variables are altered by perturbing water with cellulose polymers: $\mathrm{pH}$; electric conductivity; heat of mixing with acids or bases; density; and spectra, i.e., its ultraviolet (UV) and visible (vis) light absorption and fluorescence spectra, and its infrared spectra; images obtained with atomic force microscopy, fluorescence microscopy or optical microscopy.
} 
squeezing it, clumps of interfacial water rupture and disperse into the bulk liquid [2]. Or when we iteratively filter water through cellulose nitrate filters, the powerful flow of water in the very thin pores of the filter breaks the lumps of interfacial water [4]. Cellulose membranes, like other hydrophilic membranes, induce formation of hundreds of micrometers $(\mu \mathrm{m})$ wide interfacial water zone [6-8]. This region "excludes" medium-sized molecules (e.g., dyes), huge molecules (e.g., proteins), small unicellular microorganism, electrically charged microspheres with diameters of 0.5-2.0 $\mu \mathrm{m}$ [6]. For this reason, the region has been designated "Exclusion Zone" (EZ). This zone seems to consist of excimers composed of $\mathrm{H}_{2} \mathrm{O}$, which are organized in networks of ice-like layers $[9,10]$. Our conjecture is supported by our data on water repetitively brought in contact with Nafion ${ }^{\circledR}$-an inert hydrophilic membrane [11-16]. We investigated water perturbed by this film because it is well known that its EZ zone is particularly wide $[6,17,18]$ - its width may reach $1000 \mu \mathrm{m}$.

Corroborating our conjecture requires more data. For example, at this stage, investigating the membrane specificity of the perturbed water's properties is desirable. Although properties of waters perturbed with different kind of membranes resemble each other, these have some membrane specific features [2].

In this study, we aim at obtaining some of the required data. Specifically, our goals are: (1) measuring the physicochemical properties of water repetitively brought into contact with a derivative of the natural hydrophilic cellulose polymer, i.e., cellophane (CE); (2) comparing these properties to those of water repetitively brought in contact with $\mathrm{HC}$ or Nafion, which were reported in Refs. [2, 11-16]; and (3) assessing the thermal stability of the associates present in water perturbed by cellulose.

Studying water repetitively brought in contact with cellulose or Nafion is significant for many common industrial and scientific activities. In fact, in many natural or man-made systems, water is in contact with these polymers or flows adjacent to these. The properties of such water need to be known. For example, its optical activity may have implications for bioprocesses.

To pursue our goals, in "Materials and methods" section, we describe the used materials and measuring techniques. In "Results" section, we report our experimental data on water repetitively brought in contact with cellophane. We denote such water "Iteratively Perturbed Water by Cellophane" (IPW-CE). In "Samples and controls" section, we detail the samples and controls, as well as that we show that impurities cannot underlie the physicochemical properties of IPW-CE. In "Evidencing presence of molecular associates in IPW-CE" section, we report the results of our following measurements: density, calorimetric titrations, conductometric titrations, $\mathrm{pH}$, fluorescence microscopy and optical microscopy. In the supplementary information (SI) section SI2, we present our dynamic light scattering and spectroscopic analyses of IPW-CE (UV-Vis absorbance, circular dichroism and fluorescence spectra). The results evidence the presence of molecular associates in IPW-CE. In "Analyses of the molecular associates" section, we report that these associates can be isolated by lyophilizing IPW-CE, and we report the results of our following analyses of the isolated associates: MALDI-TOF: matrix-assisted laser desorption/ ionization time of flight, coupled with mass spectrometry analyses and thermogravimetric analyses. In "Samples and controls"-3.4 sections and SI2, we compare the data on IPW-CE to the related already published data on water iteratively perturbed with $\mathrm{HC}$ or Nafion, as well as that of water iterative filtrated through cellulose nitrate. In "Discussion" section, we discuss our results. In "Conclusions" section, we present our main conclusions.

\section{Materials and methods}

\section{Materials}

We used six types of cellophane sheets from Innovia Film: Natureflex 21NP, $23 \mathrm{NP}, 28 \mathrm{NP}, 31 \mathrm{NP}, 35 \mathrm{NP}$ and 42NP. These regenerated cellulose sheets have different thickness, but their chemical composition is the same. We did not observe statistically significant differences in the physicochemical properties of IPW-CE related to the thickness of the sheet with which it was prepared. Accordingly, we pooled the data obtained for IPW-CE prepared with the various sheets.

We determined the purity of the CE sheets with IC analyses (see "Ion chromatography (IC)" section). The results show that the inorganic molecules present in the calcined specimens are less than the measurements limits.

\section{Experimental design}

IPW specimens are systems far from equilibrium, selforganizing and dissipative. Consequently, their behavior is repeatable, but not quantitatively reproducible. Therefore, we applied the measurement methods described below to many specimens. Usually, many tens of specimens were measured till it was evident that we had discovered a repeatable phenomenon, e.g., a marked difference between the properties of IPW-CE versus those of IPW-HC, IPW-N and Milli- ${ }^{\circledR}$ water. 


\section{Methods}

\section{Electric conductivity measurements}

We systematically performed measurements of the specific conductivity of the samples, using a Radiometer CDM 210 conductivity meter, having a conductivity cell constant of $0.1 \mathrm{~cm}^{-1}$. Before measuring the conductivity of a sample, we calibrated the cell by determining the cell constant $K$ $\left(\mathrm{cm}^{-1}\right)$. We performed the conductometric titrations in a thermostatic room $\left(25 \pm 1^{\circ} \mathrm{C}\right)$, using samples that had been temperature conditioned in a measuring cell by a thermostat-cryostat (Grant LTD6) to within $\pm 0.1{ }^{\circ} \mathrm{C}$.

\section{Ion chromatography (IC)}

We determined the concentration of inorganic molecules, specifically halide ions, which hypothetically might be present in CE, by the following processes: We incinerated pieces of $\mathrm{CE}$ in an alkaline environment, dissolved the calcined samples in aqueous $\mathrm{HNO}_{3}$ and investigated the resulting solutions with anionic IC. The details of these processes are: We thoroughly minced a piece of CE weighing $43 \mathrm{mg}$ and subsequently mixed it with $2.5 \mathrm{~g}$ of alkaline Eschka $\left(\mathrm{MgO} / \mathrm{Na}_{2} \mathrm{CO}_{3}\right.$ in 2:1 ratio); we calcined the mixture in a muffle at $600{ }^{\circ} \mathrm{C}$, for $3 \mathrm{~h}$, in a porcelain crucible with a lid; we dissolved the calcined sample in aqueous $\mathrm{HNO}_{3} 2 \mathrm{M}$; we neutralized the resulting solution by adding aqueous $\mathrm{NaOH} 1 \mathrm{~N}$ until its $\mathrm{pH}$ was 7; to obtain a $200 \mathrm{~mL}$ solution, we added ultrapure water (conductivity $<0.06 \mu \mathrm{S} \mathrm{cm}^{-1}$ ); we investigated the presence of inorganic molecules in the solution with the APAT IRSA CNR 4020 Man 29/2003 IC method. We used a Metrohm IC 883 with conductivity detector, using an A Supp 7 column by Metrosep (250 mm length, $4.0 \mathrm{~mm}$ diameter) consisting of a stationary phase of polyvinyl alcohol functionalized by quaternary ammonium groups, with a particle size of $5 \mu \mathrm{m}$, and a mobile phase consisting of a solution of sodium carbonate $3.6 \mathrm{mM}$. We compared the IC results with those obtained by analyzing a "blank". We prepared the "blank" according to the same procedures, using the same reagents at the same quantities as those used for preparing the aforementioned solution, with the sole difference that no cellophane was added. The results show that the measured ions are below the quantification limits.

\section{$\mathrm{pH}$ measurements}

We carried out the $\mathrm{pH}$ measurements with a potentiometer-pH meter (Crison GLP 21-22), having a resolution of $\pm 0.01 \mathrm{pH}$ units. We controlled the temperature within $\pm 0.1{ }^{\circ} \mathrm{C}$ with a thermostat-cryostat (Grant LTD6).

\section{Density measurements}

We measured the density $\left(\mathrm{g} \mathrm{cm}^{-3}\right)$ of IPW-CE and of Milli- $\mathrm{Q}^{\circledR}$ water with a vibrating-tube digital density meter (model DMA 5000 by Anton Paar, Austria) with a precision of $\pm 1 \times 10^{-6} \mathrm{~g} \mathrm{~cm}^{-3}$ and an accuracy of $\pm 5 \times 10^{-6} \mathrm{~g} \mathrm{~cm}^{-3}$. We controlled the temperature of the water around the densitometer cell to $\pm 0.001 \mathrm{~K}$. We calibrated the densitometer periodically with dry air and pure water.

\section{Calorimetry}

We performed the following three kinds of experiments to determine the thermodynamic parameters for the formation of complexes between the aggregates in IPW-CE and the base (aqueous $\mathrm{NaOH}$ ):

1. Determination of the heat of dilution $\Delta H_{\mathrm{dil}}\left(m_{\mathrm{x}}^{\mathrm{i}} \rightarrow m_{\mathrm{x}}^{\mathrm{f}}\right)$ from the initial molality $\left(m^{\mathrm{i}}\right)$ to the final molality $\left(m^{\mathrm{t}}\right)$ of binary aqueous solutions of $\mathrm{NaOH}$, at the different concentrations employed.

2. Determination of the heat of dilution $\Delta H_{\mathrm{dil}}\left(m_{\mathrm{y}}^{\mathrm{i}} \rightarrow m_{\mathrm{y}}^{\mathrm{f}}\right)$ from the initial molality $\left(m^{\mathrm{i}}\right)$ to the final molality $\left(m^{\mathrm{f}}\right)$ of IPW-CE.

3. Determination of the heat of mixing $\Delta H_{\text {mix }}\left[\left(m_{\mathrm{x}}^{\mathrm{i}}\right)\left(m_{\mathrm{y}}^{\mathrm{i}}\right) \rightarrow m_{\mathrm{x}}^{\mathrm{f}}, m_{\mathrm{y}}^{\mathrm{f}}\right]$ of IPW-CE with the binary aqueous $\mathrm{NaOH}$ solutions as probes.

We obtain the values of the experimental heats (of dilution or mixing) from the equation:

$\Delta H=(\mathrm{d} Q / \mathrm{d} t) / P_{\mathrm{w}}$,

where $\mathrm{d} Q / \mathrm{d} t / \mathrm{W}$ is the heat flux and $P_{\mathrm{w}} / \mathrm{kg} \mathrm{s}^{-1}$ is the total mass flow rate of the solvent through the calorimeter. $\Delta H$ is $\mathrm{J} \mathrm{kg}^{-1}$ of solvent in the final solution. We used aqueous solutions of $\mathrm{NaOH}$ at different concentrations as probe solutions.

We monitored the heat of mixing by using a thermal activity monitor (TAM) model 2227 , by Thermometric (Sweden) equipped with a flow mixing vessel. A P3 peristaltic pump (by Pharmacia) envoys the solutions into the calorimeter through Teflon tubes. The flow rates of the two liquids are the same. The rates are constant in the inlet tubes. Therefore, the solution coming out of the calorimeter has a concentration half the initial one. The mass flow rate (constant within $1 \%$ ) amounts to $3 \times 10^{-3} \mathrm{~g} \mathrm{~s}^{-1}$. It was the same for all the experiments.

We obtain the enthalpies of mixing the two solutions (IPW-CE and aqueous $\mathrm{NaOH}$ ) by the following equations [19]: 


$$
\begin{aligned}
& \Delta H_{\text {mix }}\left[\left(m_{\mathrm{x}}^{\mathrm{i}}\right)\left(m_{\mathrm{y}}^{\mathrm{i}}\right) \rightarrow m_{\mathrm{x}}^{\mathrm{f}}, m_{\mathrm{y}}^{\mathrm{f}}\right]=\Delta H * \\
& \quad+\Delta H_{\mathrm{dil}}\left(m_{\mathrm{x}}^{\mathrm{i}} \rightarrow m_{\mathrm{x}}^{\mathrm{f}}\right)+\Delta H_{\mathrm{dil}}\left(m_{\mathrm{y}}^{\mathrm{i}} \rightarrow m_{\mathrm{y}}^{\mathrm{f}}\right) .
\end{aligned}
$$

The enthalpy of mixing of two binary solutions $\left(\Delta H_{\text {mix }}\right)$ is related to the enthalpy of formation of a complex, or in general to the enthalpy of interaction between solutes $\left(\Delta H^{*}\right)$ and to the heat of dilution experienced by the two solutes $\left(\Delta H_{\mathrm{dil}}\right)$. IPW-CE, due to the practical absence of a solute, cannot produce any contribution to the heat of dilution and mixing via the y component. Consequently, $\Delta H_{\text {mix }}\left[\left(m_{\mathrm{x}}^{\mathrm{i}}\right)\left(m_{\mathrm{y}}^{\mathrm{i}}\right) \rightarrow m_{\mathrm{x}}^{\mathrm{f}}, m_{\mathrm{y}}^{\mathrm{f}}\right]$ should coincide with $\Delta H_{\text {dil }}\left(m_{\mathrm{x}}^{\mathrm{i}} \rightarrow m_{\mathrm{x}}^{\mathrm{f}}\right)+\Delta H *$, i.e., the dilution enthalpy of the probe plus an interaction term. We can express this interaction enthalpy $\left(\Delta H^{*}\right)$ as:

$\Delta H *=\Delta H^{\mathrm{E}}$,

where $\Delta H^{\mathrm{E}}$ represents the excess enthalpy of mixing of the IPW-CE and the probe. $\Delta H^{\mathrm{E}}$ is the contribution attributed to the presence of aggregates. The hypothesis is that some strong favorable interactions take place between the $\mathrm{OH}^{-}$ions and the aggregates.

We assume that a complex of IPW-CE with $\mathrm{NaOH}$ forms. The following chemical equation represents the association process:

$\mathrm{AG}+n \mathrm{~L}=\mathrm{AGL}_{\mathrm{n}}$,

where AG denotes the aggregates, $n$ is the binding stoichiometry, and $L=\mathrm{OH}^{-} . \Delta H^{\mathrm{E}}$ is normalized to the total molality $\left(m_{\mathrm{AG}}\right)$ of the aggregates. We obtain $m_{\mathrm{AG}}$ from the conductometric titration data (see "Conductometry revealing the concentration of the molecular associates" section). $\Delta H^{\mathrm{E}}$ is a linear function of the actual molality of the titrant $\left(m_{\mathrm{L}}^{\mathrm{f}}\right)$, of the standard molar enthalpy of association $\left(\Delta H_{\mathrm{a}}^{\circ}\right)$ and of the apparent association constant $\left(K_{\mathrm{a}}^{\prime}\right)$ :

$m_{\mathrm{AG}} / \Delta H^{\mathrm{E}}=1 / \Delta H_{\mathrm{a}}^{\circ}+1 /\left(\Delta H_{\mathrm{a}}^{\circ} K_{\mathrm{a}}^{\prime} m_{\mathrm{L}}^{\mathrm{f}}\right)$.

The actual concentration of the probe is given, for each value of $\Delta H^{\mathrm{E}}$, by:

$m_{\mathrm{L}}^{\mathrm{f}}=m_{\mathrm{L}}-m_{\mathrm{AG}}$,

where $m_{\mathrm{L}}$ is the total stoichiometric molality of the probe and $\bar{x}$ is the degree of binding. $\bar{x}$ holds:

$$
\begin{aligned}
\bar{x}= & \frac{1}{2 \cdot m_{A G}}\left(m_{\mathrm{AG}}+n \cdot m_{\mathrm{L}}+1 / K_{\mathrm{a}}^{\prime}\right) \\
& -\sqrt{\left(m_{\mathrm{L}}+m_{\mathrm{AG}}+1 / K_{\mathrm{a}}^{\prime}\right)^{2}-4 \cdot n \cdot m_{\mathrm{L}} \cdot m_{\mathrm{AG}}}
\end{aligned}
$$

The standard molar enthalpy of association, the binding stoichiometry $n$ and the apparent association constant are obtained from Eqs. (5), (6) and (7) by iterative least-squares fitting of the data. We fitted the data to a single set of identical binding sites models using ORIGIN 7.0 software. The iterations are continued until two successive values of $\Delta H_{\mathrm{a}}^{\circ}$ differ by less than $2 \%$.

The values of the free energy and entropy are computed from the usual thermodynamic relations. The absence of information about the activity coefficients leads to evaluations of the association parameters that are not precisely defined thermodynamically. We can only determine an apparent association constant $K_{\mathrm{a}}^{\prime}$. Consequently, the standard free energy and entropy, respectively, $\Delta G^{\circ \prime}{ }_{\text {a }}$ and $\Delta S^{\circ \prime}{ }_{\text {a }}$, suffer from the same limitations.

\section{Fluorescence microscopy}

The illumination source of the microscope with which we carried out the fluorescence measurements is a $100 \mathrm{~W}$ Hg lamp. We employed a set of dichroic filters to select a specific wavelength of excitation and emission of light. We observed images generated from the emission of fluorescence both by an ocular and through a Hamamatsu ccd/ cmos $20 \times$ photo-camera via an inverted Olympus $\times 71$. The max resolution of the photo-camera was $1920 \times 1440$ pixel with a ratio of $8.26 \mathrm{pixel} / \mathrm{micron}$. We dispersed $1 \%$ in mass of polystyrene latex beads solution in a $1 \mathrm{~mL}$ of sample (IPW) and in $1 \mathrm{~mL}$ of Milli-Q ${ }^{\circledR}$ water (control) in order to observe the Brownian motion of the particles dispersed in the liquids. The beads of carboxylate-modified polystyrene had a size of $200 \mathrm{~nm}$, and each particle carried fluorescent green probes purchased from The Thermo Scientific. These ones have internally dyed microsphere suspensions that feature bright, high contrast colors emitting bright and distinct colors when illuminated by $465 \mathrm{~nm}$ light. Trace amounts of surfactant to inhibit agglomeration and promote stability are present on the surface of each bead.

\section{Optical microscopy}

We deposited a drop of IPW on a glass sample holder. We let the drop dry in air. We used a Bresser LCD Micro MP Optical Microscope to observe the dried deposit.

\section{Lyophilization}

We lyophilized IPW by freezing of samples and subsequently reducing their surrounding pressure. This allows the frozen water in the samples to sublimate directly from the solid phase to the gas phase. Lyophilization of about $100 \mathrm{~mL}$ of IPW yields a large amount ( $20 \mathrm{mg})$ of solid residue. 


\section{Matrix-assisted laser desorption/ionization time of flight (MALDI-TOF) coupled with MS}

We obtained MALDI-TOF/MS spectra by using a 4800 Plus MALDI-TOF mass spectrometer of AB Sciex. We mixed aliquots of samples $(1 \mathrm{~mL})$ directly on the sampleholding plate with an equal volume of 2,5-dihydroxybenzoic acid matrix dissolved in $70 \%$ ACN, $30 \%$ formic acid $0.1 \%\left(10 \mathrm{mg} \mathrm{mL}^{-1}\right)$. We performed the analyses in a positive mode, setting the instruments in reflector mode, in the mass range $100-2500 \mathrm{~m} / \mathrm{z}$. We set the laser power to $3500 \mathrm{~V}$ for MS spectra acquisition. Each spectrum represents the sum of 3000 laser pulses from randomly chosen spots per sample position. We performed all analyses in triplicate. We analyzed the raw data with Data Explorer Software, version 4.9 (build 115), from Applied Biosystems. We report the data as mono-isotopic masses.

\section{Thermogravimetric (TG) analyses}

We carried out the TG analyses with a TA4000 PerkinElmer apparatus. We placed the hydrophilic polymers or lyophilized samples, weighting 1-2 $\mathrm{mg}$, in an alumina crucible, and subsequently heated these from 26 to $950{ }^{\circ} \mathrm{C}$. The scan rate was $20 \mathrm{~K} \mathrm{~min}^{-1}$. We carried out the analyses in air or in a nitrogen gas $\left(\mathrm{N}_{2}\right)$ flow.

\section{Results}

\section{Samples and controls}

\section{Preparation procedure of IPW-CE}

The preparation of IPW-CE is the same as that of IPW$\mathrm{N}$. The latter is detailed in Refs. [11-16]. The procedure involves the following steps: Washing a membrane $\left(60-120 \mathrm{~cm}^{2}\right.$ surface and $50-180 \mu \mathrm{m}$ thickness) in Milli-Q ${ }^{\circledR}$ water; placing the washed membrane in $10-50 \mathrm{~mL}$ Milli-Q water (in an open polystyrene Petri dish); stirring the liquid mechanically, manually or with a magnet so that $2-3 \mathrm{~mm}$ of it laps against the membrane; taking off $1 \mathrm{~mL}$ of the liquid (away from the membrane); determining the liquid's electric conductivity $(\chi)$ and returning it to the liquid; turning over the membrane; repeating tens of times this sequence of stirring, $\chi$ measurement and membrane turnover-each time $\chi$ increased; removing the membrane and drying it in air; returning the dried membrane to the water sample; and redoing the aforementioned sequence of steps. Iteration of this cycle of membrane immersion, liquid agitation by stirring and membrane turn over, membrane removal, membrane drying and membrane re-immersion. Typically, we iterated this cycle 10-20 times. The liquid, left over after the last membrane removal step, is called "iteratively perturbed water" (IPW). The preparation procedure of IPW-HC resembles that of IPW-CE or IPW-N [2]. The sole differences are that $\mathrm{HC}$ after its immersion in water is squeezed and the water is not stirred.

We characterize the various IPW samples by their electric conductivity $\left(\chi_{\mathrm{IPW}}\right)$. The advantages of $\chi$ measurements are that these are fast, nondestructive, non-polluting and reliable. These advantages enabled us to reliably expound the properties of IPW.

$\chi_{\mathrm{IPW}}$ depends on the total number of the cycles of immersion and removal of the polymer, the dimension of the polymer, the volume of the involved liquid water and the ambient conditions. $\chi_{\text {IPW }}$ always increases with the number of cycles. After a few iterations of the sequence "liquid agitation by stirring, membrane turn over and $\chi$ measurement," the enhancement of $\chi_{\mathrm{IPW}}$ surpasses the experimental error.

\section{Impurities analyses}

Impurities released by the membrane do not underlie $\chi_{\text {IPW }}$ phenomena. It might be that our preparatory washing of the membranes had been insufficient for releasing all its electrolytic impurities. Still, these would get released during the initial cycles of immersion. The release of electrolytes should exponentially decrease after a few cycles. Yet, $\chi_{\mathrm{IPW}}$ increases with each cycle.

An additional argument against impurities released by the membrane underlying the typical $\chi_{\mathrm{IPW}}$, as well as other physicochemical phenomena of IPW-CE, is that these phenomena are unchanged if you are using brand new pieces of membranes or you are using again and again the same membrane for months and months. Many reuses, over the course of several months, do not affect the phenomena. We found the same for IPW-HC and for IPW-N $[2,15]$.

The operator contaminating the samples, and thus enhancing $\chi_{\mathrm{IPW}}$ with each cycle, is easy refutable: IPW-CE and IPW-HC are alkaline, but IPW-N is acidic $[2,12]$.

The huge differences between $\chi$ of IPW samples and that of Milli-Q cannot be due to impurities. In fact, we prepared thousands of IPW samples. $\chi$ of Milli-Q is about $1-2$ micro-Siemens per centimeter $\left(\mu \mathrm{S} \mathrm{cm}^{-1}\right) \cdot \chi_{\mathrm{IPW}}$ of IPW-CE samples may reach values as high as $2422 \mu \mathrm{S} \mathrm{cm}^{-1}$ (see Table SI1). $\chi_{\text {IPW }}$ of IPW-HC samples may reach values of about $6600 \mu \mathrm{S} \mathrm{cm}^{-1}$ [2]. $\chi_{\mathrm{IPW}}$ of IPW-N samples may reach values of about $1000 \mu \mathrm{S} \mathrm{cm}^{-1}$ [15]. For comparison, we note that preparing an aqueous electrolyte solution with $\chi=6660 \mu \mathrm{S} \mathrm{cm}^{-1}$ requires adding several thousand milligram per liter $\left(\mathrm{mg} \mathrm{L}^{-1}\right)$ of electrolyte to water, e.g., about $3500 \mathrm{mg} \mathrm{L}^{-1}$ of potassium chloride $(\mathrm{KCl})$. The inert $\mathrm{CE}$, $\mathrm{HC}$ or Nafion polymers do not release such amounts of electrolytes. 


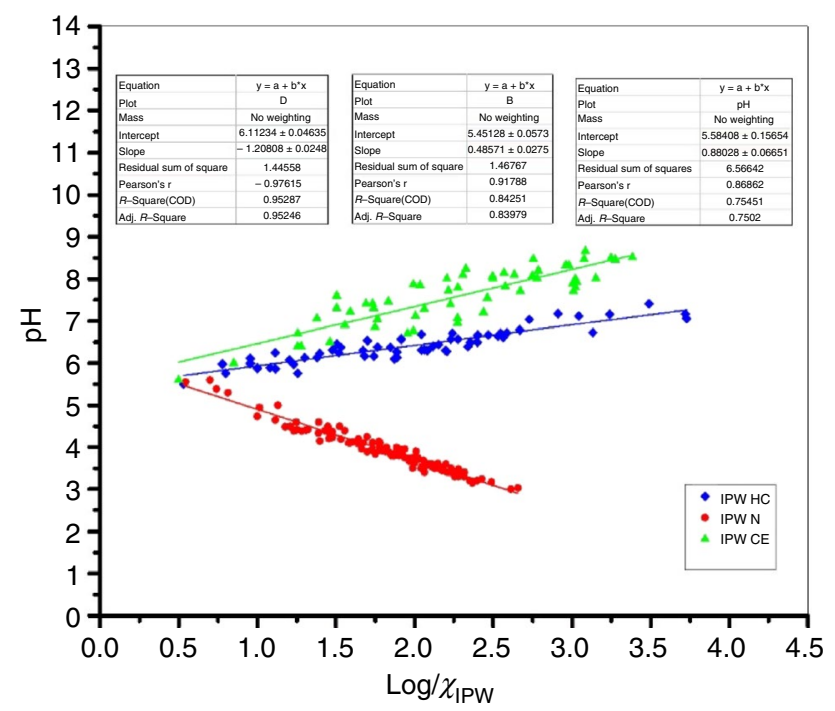

Fig. $1 \mathrm{pH}$ as a function of $\log \chi_{\mathrm{IPW}}$. The details of the linear correlation between the $\mathrm{pH}$ and the $\log \chi_{\mathrm{IPW}}$ for IPW-CE, IPW-HC and IPW-N are presented in the insets. The data for IPW-HC and for IPW-N are first reported in Refs. [2, 16]

Our ion chromatography (IC) shows that ionic impurities or ions released by CE or $\mathrm{HC}$ in, respectively, IPW-CE or IPW-HC are below the quantification limit (for IPW-CE, see "Ion chromatography (IC)" section; for IPW-HC, see Ref. [2]). IC analyses have a detection of about $10^{-1} \mathrm{mg}$ per gram ( $\mathrm{mg} \mathrm{g}^{-1}$ ), e.g., for $\mathrm{F}^{-}$ions, it is $0.02 \mathrm{mg} \mathrm{g}^{-1}$, for $\mathrm{Cl}^{-}$ions, it is $0.1 \mathrm{mg} \mathrm{g}^{-1}$, and for $\mathrm{SO}_{4}^{-}$ions, it is $0.1 \mathrm{mg} \mathrm{g}^{-1}$. The analyses of IPW-N show that it only contains $10^{-6} \mathrm{~mol} \mathrm{~L}^{-1} \mathrm{~F}^{-}$and $\mathrm{SO}_{4}{ }^{2-}$ ions released by the membrane [15].

Impurities cannot underlie the dependence of $\chi_{\mathrm{IPW}}$ on storage time. While we stored IPW samples for many days or months, their $\chi_{\mathrm{IPW}}$ may show different behaviors: initially increase and then decrease, at the beginning decrease and later increase, incessantly increase or decrease (see Fig. S1 in Ref. 2 or Fig. 1 in Ref. 16). It is obvious that the concentration of impurities cannot change in this manner, increasing first, decreasing then, increasing again and so on. Instead, the dependence of $\chi_{\mathrm{IPW}}$ versus storage time is typical of dissipative, self-organizing systems that are far from equilibrium. In fact, accordingly, the experimental values measured for this kind of systems depend on the environment and on the size of the samples (see Fig. S1 in Ref. 2).

\section{Characterization of samples}

IPW being dissipative, self-organizing systems, that are far from equilibrium, implies that it is impossible to prepare samples with identical $\chi_{\text {IPW }}$ values $[2,15]$; analogously, this is true for its other physicochemical variables, like density, heat of mixing or $\mathrm{pH}$. In addition, it implies that

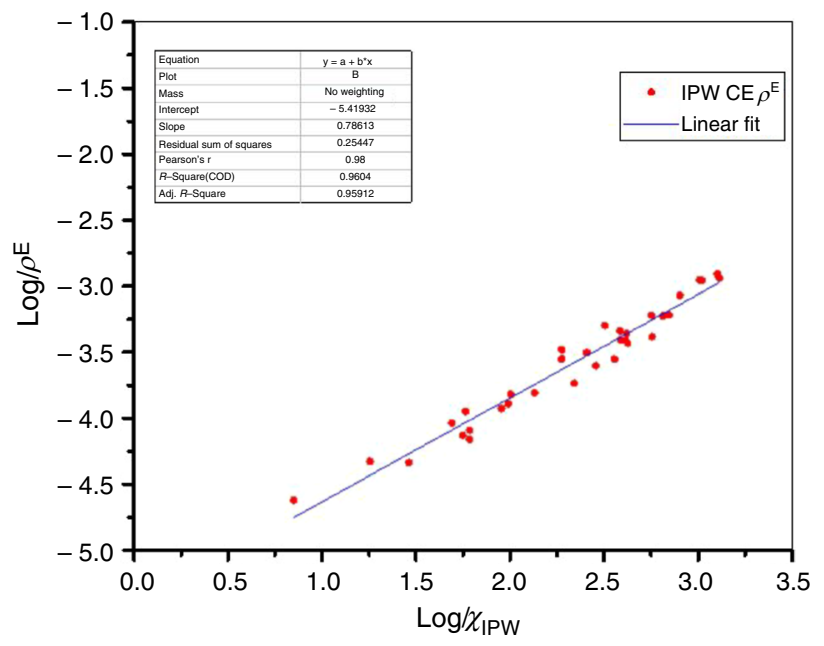

Fig. 2 The linear correlation between $\log \rho^{\mathrm{E}}$ and $\log \chi_{\text {IPW }}$ of IPW$\mathrm{CE}$

measurement techniques affect the chemistry and the physics of the samples. However, the effects of the measuring technique are inessential for revealing the distinctive physicochemical phenomena of IPW, because the values of the various physicochemical variables are correlated. For example, a linear correlation exists between $\log \chi_{\mathrm{IPW}}$ and the $\mathrm{pH}$ of IPW, as shown in Fig. 1. The details of the linear correlation, however, are perturbing membrane specific. Figure 1 shows that their slopes differ. $\log \chi_{\mathrm{IPW}}$ is also linearly cor-

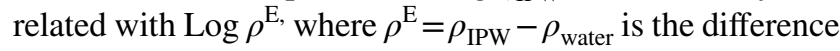
between the density of IPW $\left(\rho_{\text {IPW }}\right)$ and the density of the Milli- ${ }^{\circledR}$ water $\left(\rho_{\text {water }}\right)$ with which the IPW was prepared (for IPW-CE, see Fig. 2 and for IPW-HC, see Fig. S3 in Ref. 2). The details of the linear correlation between $\log \rho^{\mathrm{E}}$ and $\log \chi_{\text {IPW }}$ depend on the perturbing membrane.

This kind of correlations between widely varying variables indicates that the phenomena of IPW are driven by a single origin $[2,15]$. The aforementioned correlations reveal the fractal features of this liquid [5]. The self-similarity of the various IPWs indicates their complex molecular dynamics. A possible theoretical frame (see Section S6 of Ref. 2) is connected to the isomorphism of the coherent state dynamics and the self-similarity of fractals (see Ref. [5]).

Since IPW is a far from equilibrium, self-organizing, dissipative system, it exhibits phenomena that are repeatable but not quantitatively reproducible $[2,15]$. One cannot measure multiple variables for a sample with a definite $\chi_{\mathrm{IPW}}$. Many days are necessary to perform such different experiments. Sometimes, it may involve changes in laboratory facilities. The $\chi_{\mathrm{IPW}}$ of the sample varies during such time intervals and shifting ambient conditions. Therefore, to reveal characteristics of IPW-CE, we report physicochemical variables for a few samples with different $\chi_{\mathrm{IPW}}$. We did 
the same for IPW-HC and IPW-N, respectively, in Ref. [2, $11-16]$.

\section{Controls}

We use as a control the Milli-Q water with which we prepare IPW-CE. It is well known that cellulose is not soluble in water [1]. As a result, measurable differences between these liquids are attributable to changes triggered by the perturbations.

Additional controls are IPW-HC and IPW-N. Throughout the extended preparation procedure of these liquids, which may last several days, impurities may enter the liquid. IPW-CE's preparation procedure is the same as that of IPW-N, and it is very similar to that of IPW-HC (see "Preparation procedure of IPW-CE" section). Consequently, the wide variety of experimental data on IPW-HC and IPW-N, described in our preceding experimental works, are adequate controls.

\section{Evidencing presence of molecular associates in IPW-CE}

The significant increase in $\chi_{\mathrm{IPW}}$ with each membrane immersion cycle is commensurate with our conjecture of formation of molecular associates in IPW, i.e., stabilization of interfacial EZ water that ruptures during the stirring or squeezing of the membranes [2, 3, 11-16, 20, 21]. In other words, the increase in $\chi_{\text {IPW }}$ with each membrane immersion cycle is not due to an enhancement in ionic strength. Instead, we attribute it to an enhancement in proton $\left(\mathrm{H}^{+}\right)$and/or hydroxyl $\left(\mathrm{OH}^{-}\right)$ions mobility via the Grotthus jumping mechanism [22-24]. Conceivably, the associates facilitate much longer jumps than those occurring in non-perturbed water. To the best of our knowledge, IPW is the first exemplar of an aqueous liquid, for which $\chi$ increases due to an enhancement in the mobility of $\mathrm{H}^{+}$and/or $\mathrm{OH}^{-}[20,21]$.

In the following, we show that our conjecture is commensurate with the density, heat of mixing, conductometric titrations, $\mathrm{pH}$, fluorescence microscopy and optical microscopy data of IPW-CE. To elucidate the perturbing membrane specificity of the data, we compare the last ones with those published for IPW-HC and for IPW-N.

\section{Density data}

The density of IPW $\left(\rho_{\text {IPW }}\right)$ is significantly larger than that of Milli-Q ${ }^{\circledR}$ water $\left(\rho_{\text {water }}\right)$-for IPW-CE, see Fig. 2 and Table SI2, for IPW-HC, see Fig. S3 in Ref. 2, and for IPW-N, see Fig. 2 in Ref. 16. The specifications of our Anton Paar densimeter indicate the significance of the density data. In addition, their significance is revealed by the linear correlation

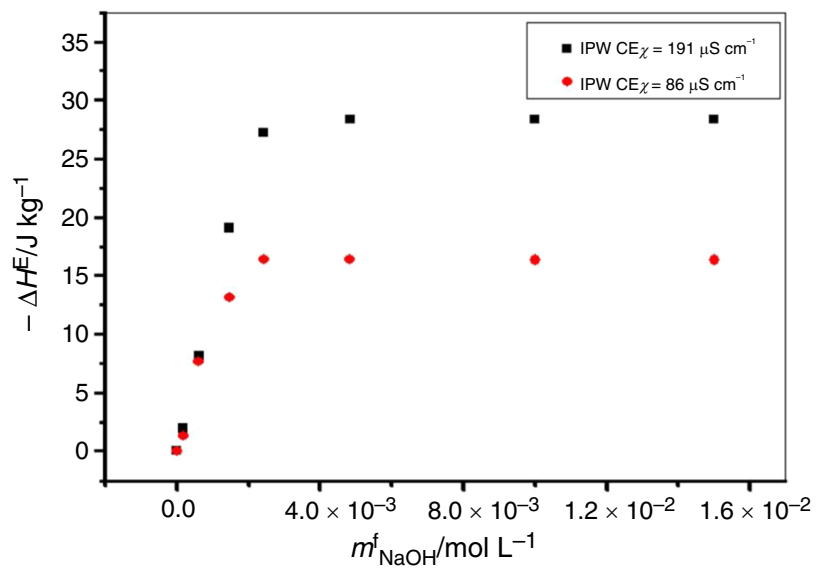

Fig. $3 \Delta H^{\mathrm{E}}$ of IPW-CE versus $m_{\mathrm{NaOH}}^{\mathrm{f}}\left(=\mathrm{mol} \mathrm{L}^{-1}\right)$. The conductivity of the two samples is given in the inset

between $\log \rho^{\mathrm{E}}=\log \left(\rho_{\mathrm{IPW}}-\rho_{\text {water }}\right)$ and $\log \chi_{\mathrm{IPW}}($ see Fig. 2).

$\rho^{\mathrm{E}}$ resembles that of an aqueous electrolyte solution [25], e.g., an aqueous $\mathrm{NaCl}$ solution with a concentration of at least 0.5 M. In "Impurities analyses" section, we reported that our impurity analyses did not reveal presence of electrolytic contaminants in IPW-CE above the detection limit. The same holds for IPW-HC [2]. Moreover, the concentration of fluorine $\left(\mathrm{F}^{-}\right)$and sulfate $\left(\mathrm{SO}_{4}{ }^{2-}\right)$ ions in IPW-N is of the order of $10^{-6} \mathrm{M}$. Such low concentrations of ions cannot underlie its significant $\rho^{\mathrm{E}}$ values [16].

Association of molecules could underlie $\rho^{\mathrm{E}} \gg 0$. For example, water molecules $\left(\mathrm{H}_{2} \mathrm{O}\right)$ could associate. Moreover, immersion of membranes in water might affect its prevalence of airborne molecules and trigger their association. For EZ water adjacent to Nafion, its density has been derived from molecular refraction data [17]. The derivation indicates that its density is at least $\sim 17 \%$ higher than of bulk water. Thus, for IPW-N, $\rho^{\mathrm{E}} \gg 0$ indeed is commensurate with our conjecture that this liquid contains clumps of ruptured EZ water [16]. To affirm that also, the $\rho^{\mathrm{E}}$ values of IPW-CE and IPW-HC may be related to the density of EZ water adjacent to, respectively, $\mathrm{CE}$ or $\mathrm{HC}$, measurements of the density of these EZs are called for.

\section{Calorimetry revealing formation of complexes}

Figure 3 and Table SI3 present the results of calorimetric titrations of two IPW-CE samples, i.e., the mixing enthalpy $\left(\Delta H^{\mathrm{E}}\right)$ of IPW-CE with sodium hydroxide solutions. $\Delta H^{\mathrm{E}}$ is defined in "Calorimetry" section. We denote by the concentration of $\mathrm{NaOH}$ in the titrated solution $m_{\mathrm{NaOH}}^{\mathrm{f}}\left(=\mathrm{mol} \mathrm{L}^{-1}\right)$. All the IPW-CE samples studied show the same trend. The heat of mixing IPW-CE with $\mathrm{HCl}$ is very low compared to $\Delta H^{\mathrm{E}}$. It is too low to enable receiving significant data. 
Table 1 Thermodynamic parameters for the complex formation between the associates in IPW-CE and $\mathrm{OH}^{-}$ions at $298 \mathrm{~K}^{\mathrm{a}}$

\begin{tabular}{lclllll}
\hline System & $\chi_{\mathrm{IPW}}^{\mathrm{i}} / \mu \mathrm{S} \mathrm{cm}^{-1}$ & $N$ & $K_{\mathrm{a}}^{\prime}$ & $-\Delta H_{\mathrm{a}}^{\circ} / \mathrm{kJ} \mathrm{mol}^{-1}$ & $-\Delta G_{\mathrm{a}}^{\circ} / \mathrm{kJ} \mathrm{mol}^{-1}$ & $T \Delta S_{\mathrm{a}}^{\circ} / \mathrm{kJ} \mathrm{mol}^{-1}$ \\
\hline IPW-CE & 86 & 1 & $1927 \pm 478$ & $52 \pm 2$ & $18.7 \pm 0.6$ & $-33 \pm 3$ \\
IPW-CE & 191 & 1 & $1234 \pm 359$ & $65 \pm 4$ & $17.6 \pm 0.7$ & $-47 \pm 5$ \\
\hline
\end{tabular}

${ }^{\mathrm{a}} \chi_{\mathrm{IPW}}^{\mathrm{i}}$ is defined in the text. $n, K_{\mathrm{a}}^{\prime},-\Delta H_{\mathrm{a}}^{\circ},-\Delta G_{\mathrm{a}}^{\circ}$ and $\Delta S_{\mathrm{a}}^{\circ}$. are defined in "Calorimetry" section

$n$ is the binding stoichiometry. $K_{\mathrm{a}}^{\prime}$ represents the apparent association constant. $-\Delta H_{\mathrm{a}}^{\circ}$ represents the standard molar enthalpy of association. $-\Delta G_{\mathrm{a}}^{\circ}$ represents the standard free energy. $\Delta S_{\mathrm{a}}^{\circ}$ represents the standard entropy. $T$ represents the temperature in degrees Kelvin (K)

Fig. 4 Conductometric titrations of IPW-CE with $\mathrm{HCl}$. a, b present the titration curves of $\chi$ versus $M_{\mathrm{HCl}}^{\mathrm{f}} \mathrm{mol} \mathrm{L}^{-1}$ for samples with $\chi_{\mathrm{IPW}}^{1}=86 \mu \mathrm{S} \mathrm{cm} \mathrm{cm}^{-1}$ and $\chi_{\mathrm{IPW}}^{\mathrm{i}}=191 \mu \mathrm{S} \mathrm{cm}^{-1}$, respectively

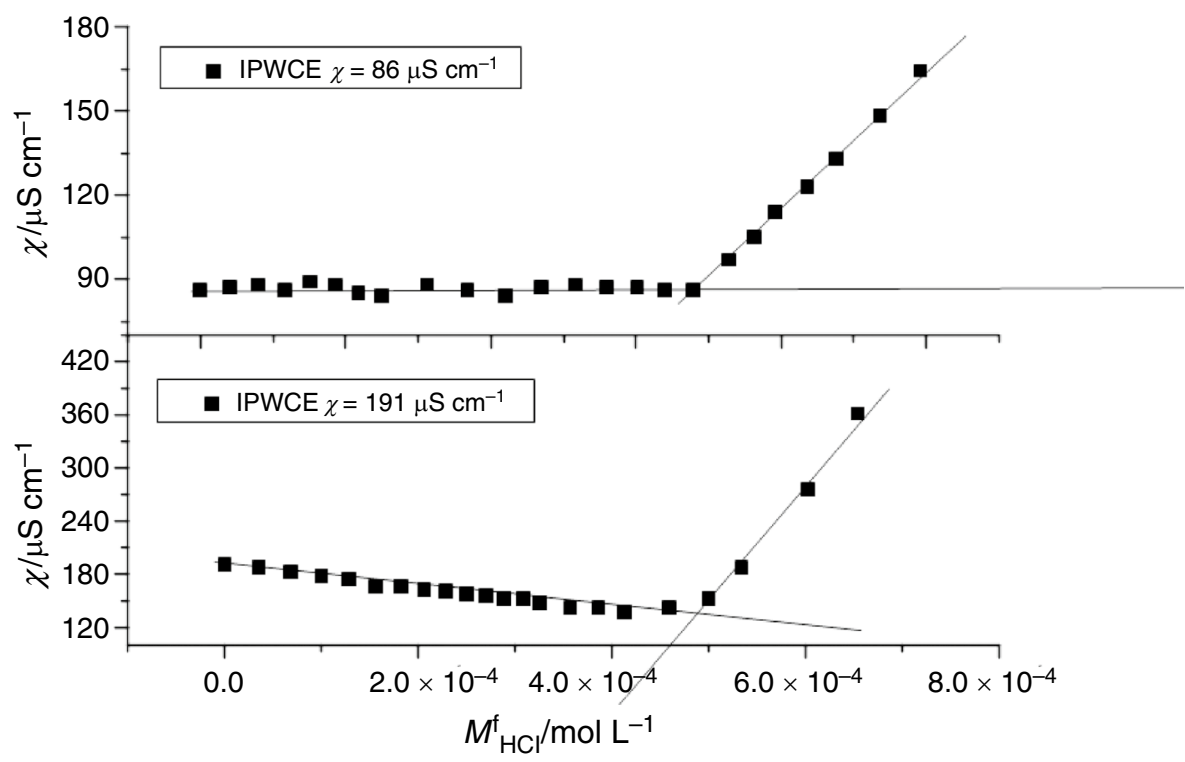

The calorimetric titration curves in Fig. 3 display a plateau, with a trend that can be described as a rectangular hyperbola, characteristic of complex formation [19]. As such, the calorimetric titration curve hints at interactions between $\mathrm{OH}^{-}$and the molecular aggregates in IPW-CE. The thermodynamic parameters shown in Table 1 indicate that the driving force to the complex formation is of enthalpic nature. The values of the enthalpy of association as well as the entropies are high and negative. (These values are defined in "Calorimetry" section.) The values of free energy are not very high, essentially due to the enthalpy-entropy compensation.

The simplistic reasoning of impurities underling the calorimetric data is refutable by the results and arguments presented in "Impurities analyses" section. Moreover, the data resemble the calorimetric titrations of $\mathrm{NaOH}$ mixed with IPW-HC [2] or with IPW- $\mathrm{F}_{\text {cellulose nitrate }}$ [3]. The calorimetric titrations curves of the aforementioned IPWs are similar. The curves do not contain features attributable to the differences of the perturbation methods or perturbing membrane.

The kind of interactions existing between $\mathrm{OH}^{-}$and the molecular associates in IPW-CE or in other IPW types, hitherto, remains an enigma. We have studied these liquids with a variety of techniques. However, the available data are insufficient for determining the chemical composition of the associates, the molecules constituting the associates and their supramolecular structure. Explaining the calorimetric data of the various types of IPW, as well as most of their other phenomena, requires additional research.

The reported errors are the standard deviations as obtained by fitting the data to Eq. (5) in "Calorimetry" section. Errors are half the range of $\Delta G_{\mathrm{a}}^{\circ}$ calculated from the upper and lower error in $K_{\mathrm{a}}^{\prime}$. Errors are the sum of the errors on free energy and enthalpy. 
Fig. 5 Schematic images of the charge distribution in water adjacent to a Nafion membrane (a) and to a CE membrane (c). Fluorescent microscope pictures of IPW-N (b) and of IPW-CE (d) (a)

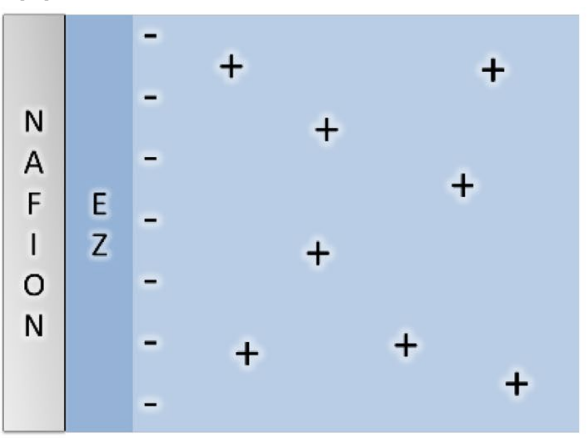

(c)

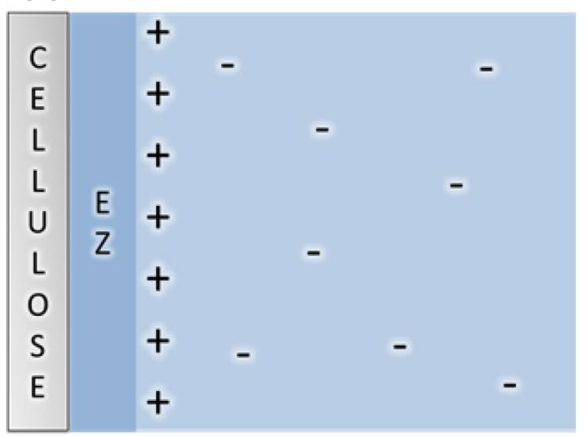

(b)

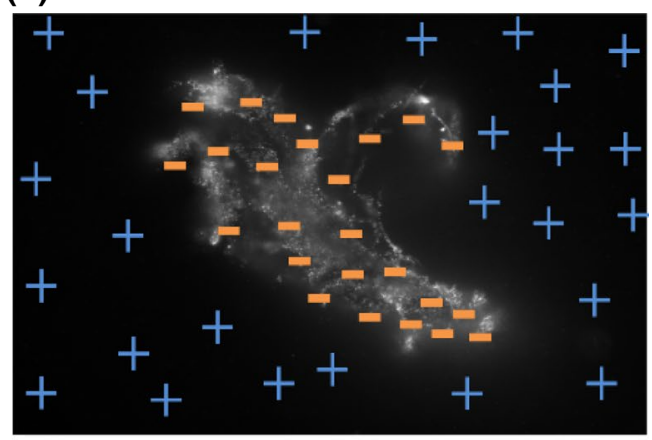

(d)

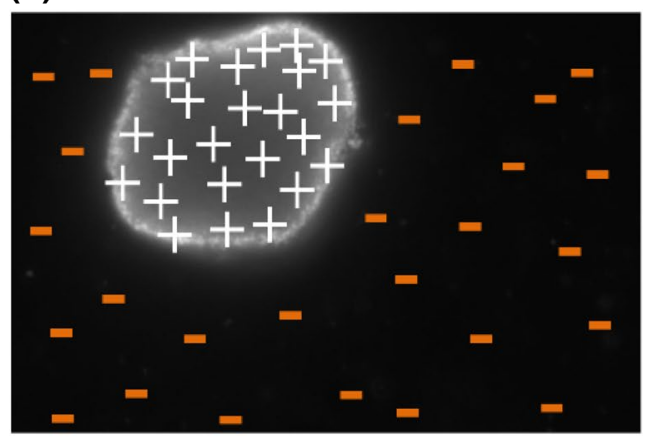

\section{Conductometry revealing the concentration of the molecular associates}

Figure 4 depicts the conductometric titration data obtained by adding $\mathrm{HCl}$ to IPW-CE $(1-3 \mathrm{~mL})$. The figure displays $\chi$ versus the titrant concentration, $M_{\mathrm{HCl}}^{\mathrm{f}} \mathrm{mol} \mathrm{L}{ }^{-1}$, in the titrated solution. The titrations resemble those of a strong acid with a weak base. The equivalent point indicates that the concentration of the entities is of the order of $10^{-4} \mathrm{~mol} \mathrm{~L}^{-1}$.

The naive reasoning that impurities constitute the entities can be countered by the results and contentions presented in "Impurities analyses" section. Moreover, the titration curves of Fig. 4 resemble those of IPW-HC with $\mathrm{HCl}$ [2]. Furthermore, the titration data are commensurate with our conjecture that the entities present in IPW are molecular associates, i.e., ruptured clumps of interfacial EZ water. The differences in the concentrations of the entities in the various types of IPW, revealed by the data, are explainable within the context of the conjecture. The concentration of the entities in IPW-CE is an order of magnitude less than that of IPW-HC. To determine the concentration of entities in IPW-N, we have titrated it with $\mathrm{NaOH}$ [13], because IPW-N is acidic (see Fig. 1). The concentration of the entities in IPW-N is of the same order that of IPW-CE [13]. We attribute the much smaller concentration of entities in IPW-CE or IPW-N compared to that in IPW-HC (about one order of magnitude) to differences in the surface area of their perturbing membranes.

\section{pH of IPW}

The $\mathrm{pH}$ of IPW-CE and of IPW-HC increases with the number of immersions of the polymer in water-see Fig. 1. The $\mathrm{pH}$ of the former can reach values as high as $8-9$, while the maximum value of the latter is about 7.5. In contrast, the $\mathrm{pH}$ of IPW-N decreases with each immersion and can reach values as low as 3-see Fig. 1.

IPW-N samples having a pH as low as 3 cannot be due to impurities. The $\mathrm{pH}$ measurements are carried out with an electrode which is sensitive to the concentration of protons $\left[\mathrm{H}^{+}\right]$. A pH of 3 means that $\left[\mathrm{H}^{+}\right]=1 \times 10^{-3} \mathrm{~mol} \mathrm{~L}^{-1}$. The dissociation constant of unperturbed water $\left(K_{\mathrm{w}}\right)$ equals $\left[\mathrm{H}^{+}\right] \times\left[\mathrm{OH}^{-}\right]=10^{-14}$, where $\left[\mathrm{OH}^{-}\right]$symbolizes the concentration of $\mathrm{OH}^{-}$. $\left[\mathrm{H}^{+}\right] \approx 10^{-3} \mathrm{~mol} \mathrm{~L}-1$ implies $\left[\mathrm{OH}^{-}\right] \approx 10^{-11} \mathrm{~mol} \mathrm{~L}-1$. In other words, $\left[\mathrm{H}^{+}\right]$is many orders of magnitude higher than $\left[\mathrm{OH}^{-}\right]$. Electric neutrality requires a concentration of counter ions (anions) of the order of $\left[\mathrm{H}^{+}\right]$. Chemical analyses of Nafion membranes and of IPW-N should easily reveal such a high concentration of negatively charged impurities. However, we did not detect anions at concentrations above $10^{-6} \mathrm{~mol} \mathrm{~L}^{-1}$ in IPW-N [15].

The $\mathrm{pH}$ of about $8-9$ of IPW-CE cannot be attributed to impurities. A pH of 8 means $\left[\mathrm{H}^{+}\right]=1 \times 10^{-8} \mathrm{~mol} \mathrm{~L}^{-1}$. A $K_{\mathrm{w}}$ of $\sim 10^{-14}$ implies that $\left[\mathrm{OH}^{-}\right] \approx 1 \times 10^{-6} \mathrm{~mol} \mathrm{~L}^{-1}$. Thus, the excess of $\left[\mathrm{OH}^{-}\right]$is two orders of magnitude larger that of $\left[\mathrm{H}^{+}\right]$. For IPW-CE to be electrical neutral, $\sim 10^{-6} \mathrm{~mol} \mathrm{~L}^{-1}$ of positive ions should be present, such as $\sim 10^{-6} \mathrm{~mol} \mathrm{~L}^{-1}$ of 
Fig. 6 Optical microscopy images of IPW. a-d Images of IPW-CE samples with $\chi_{\text {IPW-CE }}$ of, respectively, $128 \mu \mathrm{S} \mathrm{cm}^{-1}$, $170 \mu \mathrm{S} \mathrm{cm}^{-1}, 184 \mu \mathrm{S} \mathrm{cm}^{-1}$ and $242 \mu \mathrm{S} \mathrm{cm}^{-1}$, e image of IPWN. $\times 500$ enhancement. Numerous microns sized fractals structured domains are visible
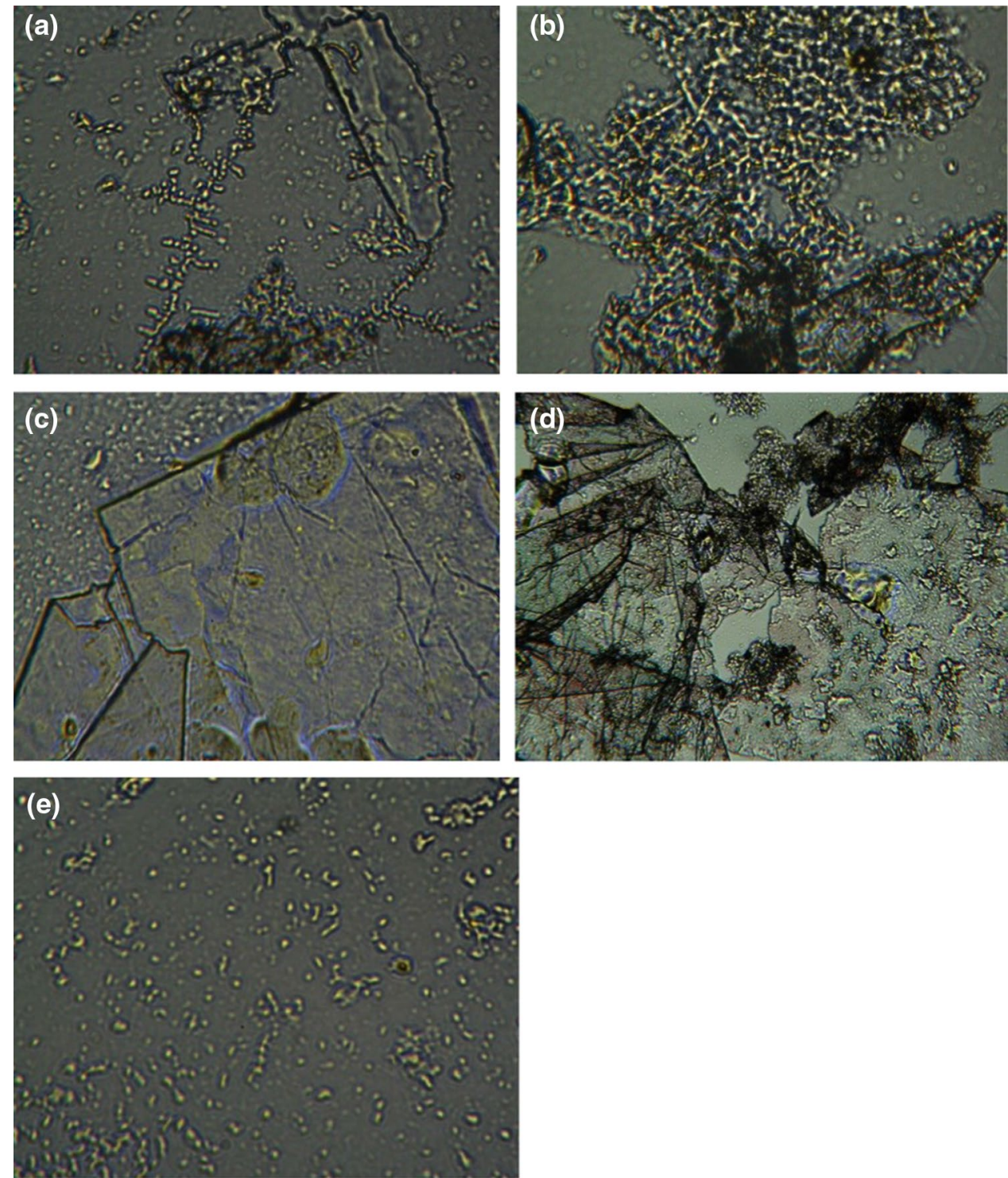

$\mathrm{Na}^{+}$. Such a high quantity is easily detectable with chemical analyses. However, our IC analyses of CE and IPW-CE did not reveal presence of $\mathrm{Na}^{+}$or other cations.

The aforementioned $\mathrm{pH}$ values are commensurate with our conjecture that the entities in IPW are clumps of ruptured EZ water. The EZ adjacent to Nafion membranes is negatively charged, while the water at the outside edge of their EZ is positively charged and has a $\mathrm{pH}$ of about 3 , as we schematically depicted in Fig. 5a. This figure is based on data of Refs. 6 and 17. Accordingly, a plausible model for IPW-N is that of negatively charged ruptured EZ clumps surrounded by bulk water containing an excess of $\mathrm{H}^{+}$, as schematically depicted in Fig. 5b. This figure is based on Fig. 5 in Ref. 16, which depicts polystyrene spheres dispersed in IPW-N. That figure showed that in IPW-N, irregular shaped $\sim 10^{2} \mu \mathrm{m}$ sized structures are present. The marked polystyrene spheres appear to be clustered at the structures.
Based on $\mathrm{pH}$ data, we assumed that the structures (which we conjectured to be ruptured EZ) are negatively charged [12]. Their surrounding bulk water is positively charged due to its excess of protons.

The effect of $\mathrm{CE}$ or $\mathrm{HC}$ on the charge distribution in their interfacial EZ water, to the best of our knowledge, has not yet been measured. The alkalinity of IPW-CE and IPW-HC hints that these liquids contain positive charged bunches of broken EZ distributed in bulk water which has an excess of $\mathrm{OH}^{-}$, as we schematically modeled in Fig. 5d. This figure, which is a schematized fluorescent microscope picture of IPW-CE, shows that in IPW-CE, $\sim 10^{2} \mu \mathrm{m}$ sized structures are present on which the marked polystyrene spheres appear to be clustered. This model of IPW-CE is inspired by the experimental findings on metal sheets. The EZ adjacent to reactive metal sheets is positively charged [26]. The bulk 
Fig. 7 Appearance of gel-like $R_{\mathrm{IPW}-\mathrm{CE}}(\mathbf{a})$ and solid $R_{\mathrm{IPW}-\mathrm{CE}}(\mathbf{b})$
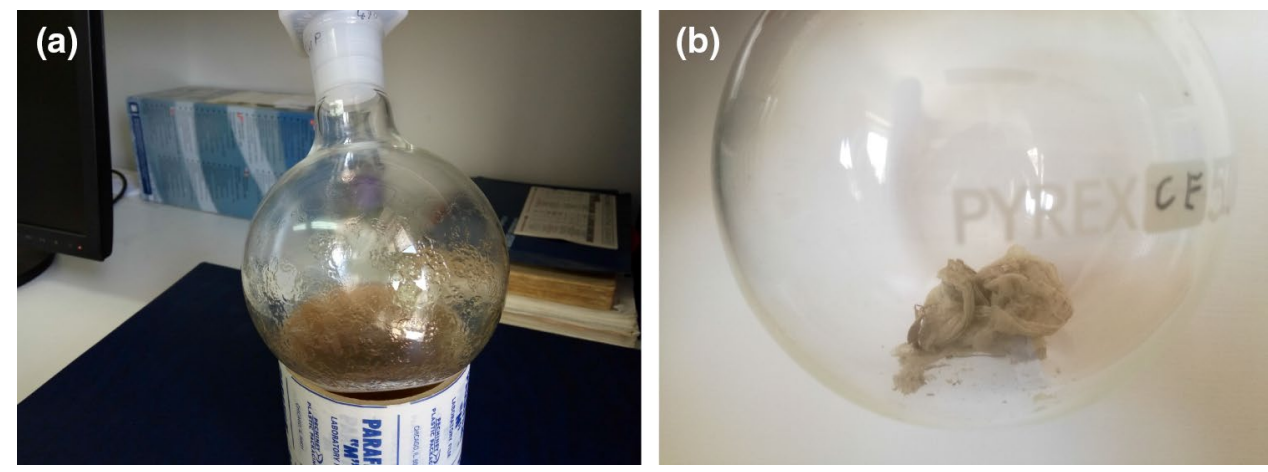

water at the external boundary of their EZ is basic ( $\mathrm{pH}$ of 8-9), which resembles that of IPW-CE.

\section{Optical microscopy visualizing the molecular associates in IPW}

Figure 6a-d presents optical microscopy images of IPWCE. These expound that in IPW-CE, domains are present, which contain minor domains, which in turn contain smaller and smaller domains, i.e., the characteristic structure of a fractal. To evidence scale-free self-similar fractal properties of a material requires mathematical analyses. We carried out mathematical analyses (Ref. [5], Sect. 2.1.3) that show that linear correlations between the logarithmic values of broadly varying physicochemical variables of perturbed waters reveal the fractal structure of these liquids. We reported the linear correlation between $\log \chi_{\mathrm{IPW}-\mathrm{CE}}$ and the $\mathrm{pH}$ of IPW-CE ("Characterization of samples" section), as well as the linear correlation between $\log \chi_{\mathrm{IPW}-\mathrm{CE}}$ and $\log \left(\rho_{\text {IPW-CE }}-\rho_{\text {water }}\right)$ ("Characterization of samples" section). Therefore, the textures of the molecular associates in IPW-CE at least are due to the fractal nature of IPW-CE. Moreover, these appear in icy shapes of water on glass. As such, these patterns indicate that water can show a fractal organization if proper boundary conditions are realized. The above results show that IPW-CE is yet another example of a fractal structured aqueous system. ${ }^{2}$ IPW-HC, IPW-N and IPW-F also contain fractally structured domains $[2,5]$. However, the texture of the domains in the various IPWs differs, as comparisons between Fig. 6a-d and the optical microscopy of an IPW-N sample depicted in Figs. 9e and 1 in Ref. 2 show.

\footnotetext{
2 Other experimental observations of molecular fractal self-similarity in water have been reported in Refs. [27, 28]. Reference [27] concerns a $10^{-11}-10^{-3} \mathrm{~mol} \mathrm{~L}^{-1}$ serially diluted aqueous solutions. Reference [28] concerns strong electrolyte solutions.
}

\section{Analyses of the molecular associates}

\section{Isolation of the molecular associates present in IPW}

Recently, isolation of the EZ was achieved with a spontaneous phase separation technique [18]. The technique enabled isolation of the EZ which forms adjacent to CE, cellulose acetate, mixed cellulose ester or Nafion 117 membranes. The isolated EZ water, just as the EZ adjacent to the aforementioned membranes, excludes microspheres. Larger surface areas of the membranes result in formation of larger volumes of EZ adjacent to the membranes, and consequently larger volumes of the isolated EZ phase [18].

To isolate the associates in an IPW, we removed its bulk water by lyophilization. It leaves a ponderable solid residue $\left(R_{\mathrm{IPW}}\right)$. Lyophilizing $300 \mathrm{~mL}$ of IPW-CE leaves about $72 \mathrm{mg}$ of $R_{\mathrm{IPW}}$. Similar results were obtained on lyophilizing IPWHC or IPW-N [2, 14-16]. $R_{\text {IPW }}$ is stable at ambient conditions $[2,15,16]$. Figure 7 displays the residue obtained on lyophilizing IPW-CE $\left(R_{\mathrm{IPW}-\mathrm{CE}}\right)$. Its macroscopic appearance differs from that of the residues obtained on lyophilizing IPW-HC $\left(R_{\mathrm{IPW}-\mathrm{HC}}\right)$ or IPW-N $\left(R_{\mathrm{IPW}-\mathrm{N}}\right) . R_{\mathrm{IPW}-\mathrm{CE}}$ and $R_{\mathrm{IPW}-\mathrm{N}}$ have textures resembling that of a polymer, while $R_{\mathrm{IPW}-\mathrm{HC}}$ is powder like $[2,14] . R_{\text {IPW-CE }}$ is the first lyophilized IPW which sometimes is like a gel (Fig. 7a).

\section{MALDI-TOF}

Figure 8 presents the mass spectrometry data for $R_{\mathrm{IPW}-\mathrm{CE}}$, obtained with a MALDI-TOF system as ionization technique. The MALDI-TOF data for $R_{\mathrm{IPW}-\mathrm{HC}}$ and $R_{\mathrm{IPW}-\mathrm{N}}$ are presented, respectively, in Fig. S4B in Ref. 2 and in Fig. $\mathrm{S} 3$ in Ref. 15. Samples were dissolved in a polar organic solvent (methanol) and mixed with a matrix before MALDIMS analyses in reflectron positive ion mode. No spectrum in negative ion mode was observed. To obtain a better signal-to-noise ratio, different positive MALDI spectra were run and averaged, leading to the detection of several species (see Fig. 8). The mass spectrometry analyses show that $R_{\text {IPW-CE }}$ contains species with molecular 

spectrum of $R_{\text {IPW-CE. The }}$ $x$-axis represents the mass as the ratio mass/charge $(\mathrm{m} / \mathrm{z})$ of the species, and the $y$-axis The limit of detection is around $0.1 \mathrm{pmol} \mu \mathrm{L}^{-1}$. The spectrum displays primarily mass signals related to species with a molecular mass ranging from 100 to $1000 \mathrm{~m} / \mathrm{z}$
Fig. 8 MALDI-TOF mass represents the signal intensity.

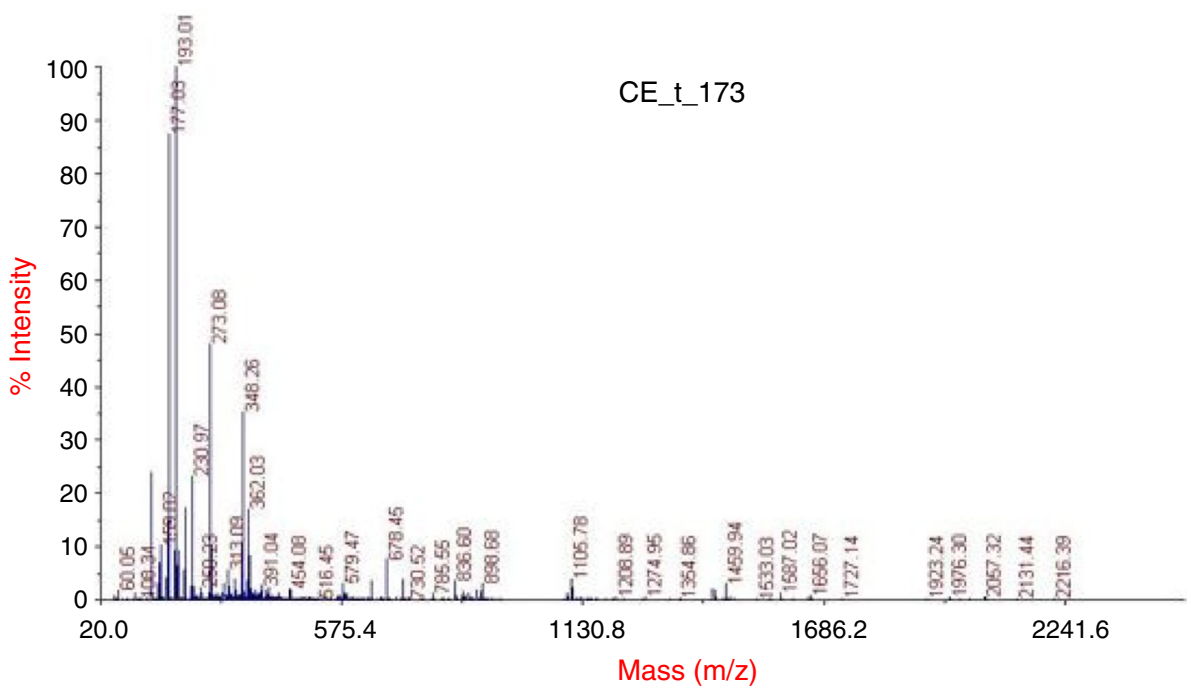

(a)

masses ranging from 100 to 1000 mass per unit charge $(\mathrm{m} / \mathrm{z})$. The most abundant species have a molecular mass below $400 \mathrm{Da}$. However, other species with higher $\mathrm{m} / \mathrm{z}$ values were detected. $R_{\mathrm{IPW}-\mathrm{CE}}$ is the first type of $R_{\mathrm{IPW}}$ wherein mass spectrometry measurements show presence of species at high molecular mass. In $R_{\mathrm{IPW}-\mathrm{HC}}$ and $R_{\mathrm{IPW}-\mathrm{N}}$, no such species with prevalence significantly above the detection limit were observed with MALDI-TOF, gas chromatograph (GC) or gel electrophoresis [2, 15]. The detection limit of MALDI-TOF is about $0.1 \mathrm{pmol} \mu \mathrm{L}^{-1}$, and that one for GC is about $0.5 \mathrm{pmol} \mu \mathrm{L}^{-1}$. The detection limit of Coomassie stain (GelCode Blue Stain Reagent, Product \# 24592) employed for gel staining is $0.25 \mathrm{ng} \mathrm{band}^{-1}$. Organic or biological matter (perhaps contaminants) constitutes less than $2 \%$ of $R_{\mathrm{IPW}-\mathrm{N}}[15]$.

The high molecular masses of the species in $R_{\mathrm{IPW}-\mathrm{CE}}$, and the fact that this solid is soluble in organic polar solvents, suggest that these species are organic molecules. Work is in progress to gain more information on the chemical nature of $R_{\mathrm{IPW}-\mathrm{CE}}$ and of the other $R_{\mathrm{IPW}}$ types.

\section{Thermogravimetry}

We studied the thermal behavior of $R_{\mathrm{IPW}}$ with thermogravimetric (TG) analyses. Figure 9 presents the TG graphs. It depicts the decomposition curves of $R_{\mathrm{IPW}-\mathrm{CE}}$ and of the perturbing pure membrane (the cellophane sheet) as a function of temperature $(T)$ at ambient pressure, i.e., it shows the percentage of mass loss of the samples as a function of $T$. Figure 9 a shows that the TG curve of $R_{\mathrm{IPW}-\mathrm{CE}}$ considerably differs from that of the CE sheet. The differences signify that the composition of $R_{\mathrm{IPW}-\mathrm{CE}}$ and that of CE are not the same, i.e., $R_{\mathrm{IPW}-\mathrm{CE}}$ and CE are differing substances. A new substance forms during the repetitive contact between water and CE. Figure $9 \mathrm{~b}$ depicts the divergence between the TG

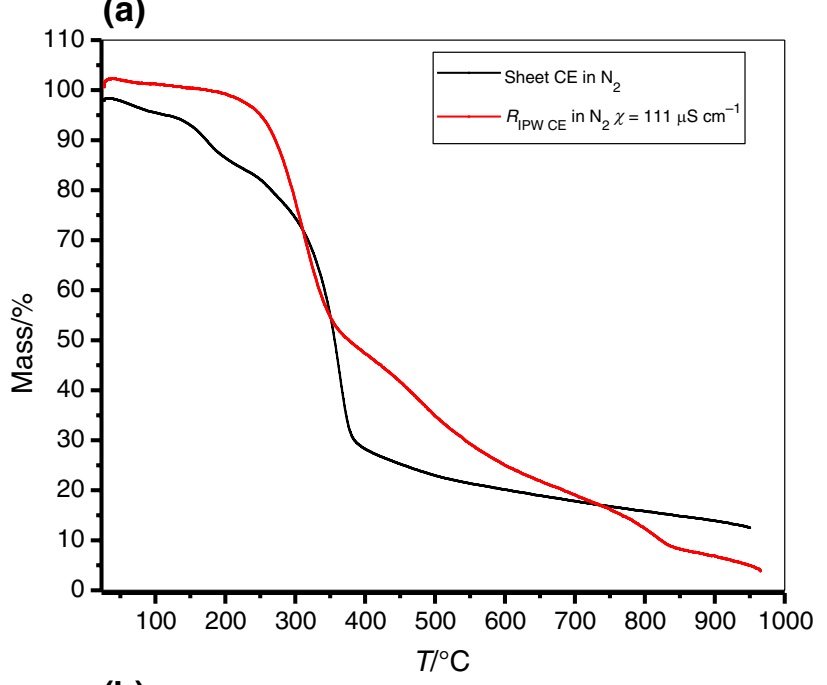

(b)

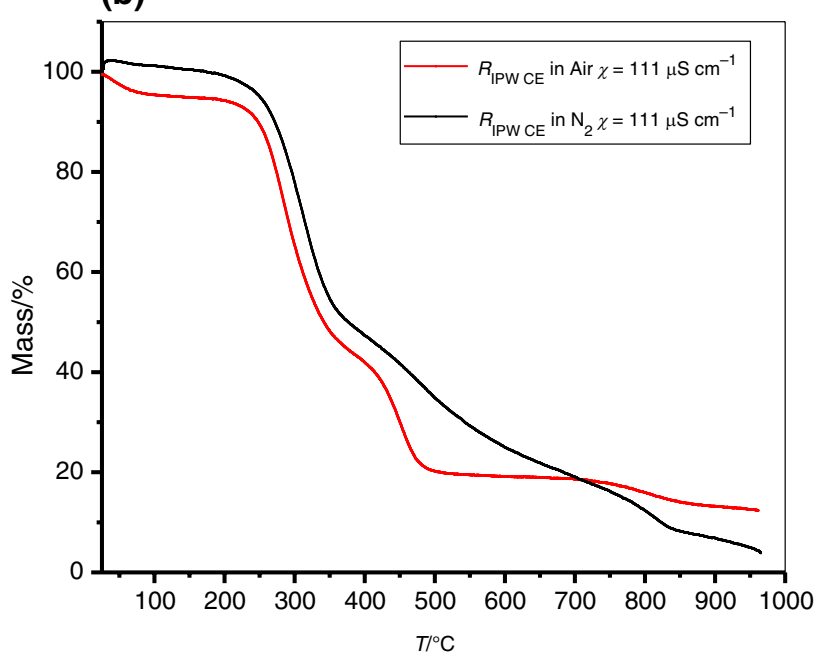

Fig. 9 a TG graphs of $R_{\mathrm{IPW}-\mathrm{CE}}$ and a CE sheet. Both materials were kept in $\mathrm{N}_{2}$, b graphs of $R_{\text {IPW-CE }}$ prepared and kept in air or in $\mathrm{N}_{2}$. The percentage of mass losses of the samples are plotted as a function of temperature $T$. For the IPW-CE sample from which the $R_{\mathrm{IPW}-\mathrm{CE}}$ was prepared $\chi_{\text {IPW-CE }}=111 \mu \mathrm{S} \mathrm{cm}^{-1}$ 
Table 2 Similarities and dissimilarities between IPW-CE, IPW-HC and IPW-N

\begin{tabular}{|c|c|c|c|c|}
\hline Property & Property is true for IPW-CE & Property is true for IPW-HC & Property is true for IPW-N & Similar \\
\hline Contains $10^{-4} \mathrm{~m}$ sized associates & Yes & Yes & Yes & Yes \\
\hline Concentration of associates & $\sim 10^{-4} \mathrm{~mol} \mathrm{~L}^{-1}$ & $\sim 10^{-3} \mathrm{~mol} \mathrm{~L}^{-1}$ & $\sim 10^{-4} \mathrm{~mol} \mathrm{~L}^{-1}$ & No \\
\hline UV absorbance typical of structured water & Yes & Yes & Yes & Yes \\
\hline $\begin{array}{l}\text { Broad UV emission band typical of excimers } \\
\text { around } 350 \mathrm{~nm}\end{array}$ & Yes & Yes & Yes & Yes \\
\hline $\begin{array}{l}\text { Broad UV emission band typical of excimers } \\
\text { around } 440 \mathrm{~nm}\end{array}$ & Yes & Yes & No & No \\
\hline Optical activity typical of $\beta$-sheets & Yes & Yes & Yes & Yes \\
\hline Optical activity resistant to prolonged heating & Yes & Yes & No & No \\
\hline Fractally structured & Yes & Yes & Yes & Yes \\
\hline $\begin{array}{l}\text { Electric conductivity higher than Milli- } Q^{\circledR} \\
\text { water }\end{array}$ & Yes & Yes & Yes & Yes \\
\hline Density higher than that of Milli- $\mathrm{Q}^{\circledR}$ water & Yes & Yes & Yes & Yes \\
\hline $\begin{array}{l}\text { Linear correlation between } \chi_{\mathrm{IPW}} \text { and other } \\
\text { physicochemical variables }\end{array}$ & Yes & Yes & Yes & Yes \\
\hline $\begin{array}{l}\text { Properties of linear correlation are perturbing } \\
\text { membrane specific }\end{array}$ & Yes & Yes & Yes & Yes \\
\hline Sign of the dependence of the $\mathrm{pH}$ on $\chi$ & Positive-liquid is alkaline & Positive-liquid is alkaline & Negative-liquid is acidic & No \\
\hline Contains solely $\mathrm{H}_{2} \mathrm{O}$ & No & Yes & Yes & No \\
\hline Contains organic polymers & Yes & No & No & No \\
\hline
\end{tabular}

curves of $R_{\text {IPW-CE }}$ prepared and kept in air or in nitrogen $\left(\mathrm{N}_{2}\right)$ gas. The divergence indicates presence of different chemical components in these two types of $R_{\text {IPW-CE }}$. Work is in progress to gain more information on their chemical nature.

The TG curve of $R_{\mathrm{IPW}-\mathrm{CE}}$ in air significantly varies from that of $R_{\text {IPW-N }}$, although these curves have some common features, as a comparison between Figs. $9 \mathrm{~b}$ and 3 in Ref. 16 shows. Both curves have points of inflection near $100{ }^{\circ} \mathrm{C}$ and near $230^{\circ} \mathrm{C}$. For $R_{\mathrm{IPW}-\mathrm{CE}}$, its TG shows that near the point of inflection at $\sim 100{ }^{\circ} \mathrm{C}$, about $5 \%$ of its mass has evaporated. For $R_{\text {IPW-N }}$, near this point of inflection, about $10 \%$ of its mass has evaporated. The analyses presented in Ref. [16] indicate that the decomposition of about $10 \%$ of $R_{\text {IPW-N }}$ during its heating up to $100{ }^{\circ} \mathrm{C}$ is attributable to evaporation of its randomly moving $\mathrm{H}_{2} \mathrm{O}$. As such, the evaporation of about $5 \%$ of $R_{\text {IPW-CE }}$ during its heating up to $100{ }^{\circ} \mathrm{C}$ likely indicates that $R_{\mathrm{IPW}-\mathrm{CE}}$ contains less randomly moving $\mathrm{H}_{2} \mathrm{O}$ than $R_{\text {IPW-N }}$. As to the point of inflection near $230{ }^{\circ} \mathrm{C}$, the analyses of Ref. [16] indicate that on heating $R_{\text {IPW-N }}$ from $\sim 100$ to $\sim 230{ }^{\circ} \mathrm{C}, \mathrm{H}_{2} \mathrm{O}$ desorbs from $\sim 10^{2} \mathrm{~nm}$ sized domains composed of $\mathrm{H}_{2} \mathrm{O}$. Analyses of dispersion forces in ensembles of $\mathrm{H}_{2} \mathrm{O}$ have shown that under certain conditions, these forces may induce part of the $\mathrm{H}_{2} \mathrm{O}$ to organize in $\sim 10^{2} \mathrm{~nm}$ sized domains [29, 30]. At ambient pressures, these domains may persist when $T$ is below their transition temperature of $227^{\circ} \mathrm{C}$. The properties of EZ water are commensurate with parts of its $\mathrm{H}_{2} \mathrm{O}$ being organized in such domains [16, 31, 32]. The TG curves indicate that on heating in air $R_{\text {IPW-CE }}$ or $R_{\mathrm{IPW}-\mathrm{N}}$ from $\sim 100$ to $\sim 230^{\circ} \mathrm{C}$, respectively, about $2 \%$ or about $48 \%$ of their mass evaporate.

The TG curve of $R_{\mathrm{IPW}-\mathrm{N}}$ has only the two aforementioned inflection points. At temperatures above the second point of inflection, i.e., in the $\sim 230{ }^{\circ} \mathrm{C}<T<650{ }^{\circ} \mathrm{C}$ range, the $\mathrm{TG}$ curve of $R_{\text {IPW-N }}$ is a negatively sloped, nearly straight line. In this temperature range, about $40 \%$ of the mass of $R_{\mathrm{IPW}-\mathrm{N}}$ evaporates. Analyses in Ref. [16] indicate that the molecules evaporating in this temperature range are $\mathrm{H}_{2} \mathrm{O}$, which are ferroelectrically ordered in $\sim 10^{2} \mu \mathrm{m}$ sized domains. Classical and quantum analyses have shown that under certain conditions, these domains stabilize in ensembles of $\mathrm{H}_{2} \mathrm{O}$ [33-35]. At pressures of $\sim 1$ Atmosphere, these domains may stabilize for $T<887^{\circ} \mathrm{C}$ [33]. The properties of EZ water are commensurate with parts of its $\mathrm{H}_{2} \mathrm{O}$ being organized in such domains [16, 31].

The TG curve of $R_{\text {IPW-CE }}$ in air, in addition to the points of inflection detailed above, has points of inflection near $350{ }^{\circ} \mathrm{C}, 400{ }^{\circ} \mathrm{C}, 470{ }^{\circ} \mathrm{C}$ and $750{ }^{\circ} \mathrm{C}$. On heating $R_{\mathrm{IPW}-\mathrm{CE}}$ from $\sim 230$ to $\sim 350{ }^{\circ} \mathrm{C}$, about $50 \%$ of its mass evaporates. On heating it from $\sim 350$ to $\sim 470{ }^{\circ} \mathrm{C}$, about $20 \%$ of its mass evaporates. TG curves of many organic compounds show that these evaporate when heated between $\sim 200$ and $\sim 450{ }^{\circ} \mathrm{C}$ [36]. Accordingly, the TG cure of $R_{\mathrm{IPW}-\mathrm{CE}}$ suggests that this residue mainly contains organic compounds. The existence of several points of inflection in the TG curves of $R_{\text {IPW-CE }}$ for $T>350{ }^{\circ} \mathrm{C}$ suggests that several organic species are present in $R_{\mathrm{IPW}-\mathrm{CE}}$. As to the $\sim 20 \%$ of $R_{\mathrm{IPW}-\mathrm{CE}}$ persisting in the range of about $470-950{ }^{\circ} \mathrm{C}$, it is possible that 
at these temperatures, the residue mainly is composed of the $\sim 10^{2} \mu \mathrm{m}$ sized domains composed of ferroelectrically ordered $\mathrm{H}_{2} \mathrm{O}$, which are also present in $\mathrm{EZ}$ water and in $R_{\mathrm{IPW}-\mathrm{N}}$. In bulk water, these domains may persist at temperatures up to $887^{\circ} \mathrm{C}$ [33]. Their thermal stability is affected by the material on which the domains are spread [16].

\section{Discussion}

The data presented in "Results" section and SI2 show that repetitively bringing Milli- ${ }^{\circledR}$ water in contact with a CE sheet, just as repetitively bringing it in contact with $\mathrm{HC}$ or cellulose nitrate or Nafion, produces molecular associates. Table 2 presents a summary of the similarities and dissimilarities of the various types of IPW and of their $R_{\mathrm{IPW}}$. The similarities, e.g., the main features of the calorimetric curves and of the UV-Vis spectra of the IPWs (see "Calorimetry revealing formation of complexes," "SI2.2.1-SI2.2.3" sections), support our conjecture that during the preparation of IPW, clumps of EZ water are disseminated in the bulk liquid. The spectra resemble those of EZ water (see sections SI2.2.1 and SI2.2.3). Some of the dissimilarities show that the characteristics of the perturbing membrane affect the physicochemical properties of IPWs and of their molecular associates. The preparation procedures of IPW with CE or Nafion as the perturbing membrane are the same. However, some of the properties of IPW-CE and IPW-N considerably differ. For example, the former is alkaline $(\mathrm{pH} \approx 8-9)$, while the latter is acidic $(\mathrm{pH} \approx 3)$. As to the dissimilarities between IPW-HC and IPW-CE or IPW-N, our current data are not adequate for attributing these to the slight differences in their preparation procedures and/or to the characteristics of their perturbing membranes.

\section{Conclusions}

In this paper, we present additional data showing that repetitive contact between water and inert hydrophilic membranes alters the physicochemical properties of the liquid. The data provide supplementary evidence for our conjecture that during the repetitive contact between water and the membranes, clumps of interfacial water rupture and disperse into the bulk liquid.

A novel finding of the present study is that some of the physicochemical properties of the perturbed waters are membrane specific. In this paper, we reported our first data on water repetitively brought in contact with cellulose (CE) sheets. We repetitively brought $\mathrm{CE}$ in contact with Milli- ${ }^{\circledR}$ water in the same manner as we had done previously for Nafion. Yet, some of the properties of the resulting perturbed waters differ. A significant difference is that the water perturbed by $\mathrm{CE}$ contains species with molecular masses ranging from 100 to $1000 \mathrm{~m} / \mathrm{z}$. No such species are detectable in waters perturbed with Nafion sheets, or with hydrophilic cotton or cellulose nitrate. However, for the latter two waters, their preparation methods differed from that of water perturbed by CE. Therefore, after finishing the current study, we investigated the properties of perturbed water, which was prepared with the same method as that of waters perturbed with CE or Nafion, yet we employed another type of cellulose sheet, i.e., paper filter [37]. The water repetitively perturbed with paper filter also contains organic compounds. For waters perturbed by $\mathrm{CE}$ or paper filter, their chemical compositions significantly differ from that of the perturbing sheets. Currently, we investigate the characteristics and the origin of the organic molecules with the high $\mathrm{m} / \mathrm{z}$ values.

Another important finding is that the associates, which are present in all the repetitively perturbed waters investigated by us, are chiral. The presence of such chiral entities is independent of the perturbation method or perturbing membrane. However, circular dichroism spectra show that the supramolecular structure of the associates is perturbing membrane specific. The specificity may be of importance for technological processes, e.g., enantioselective syntheses.

Our findings raise more questions than that these provide answers. Follow-up studies are warranted. Yet, we can conclude that repetitive contact between inert hydrophilic polymers and water does affect the liquid. The effects may be relevant for biological and technological processes wherein water is in repetitive contact with such membranes.

Acknowledgements Tamar Yinnon thanks Prof. A.M. Yinnon for his support.

Author contributions VE conceived and managed the research. RG assisted in the latter task. EN prepared the perturbed water samples and performed the electric conductivity, $\mathrm{pH}$ and density measurements. AA carried out the MALDI-TOF/MS analyses. MN carried out the thermodynamic analyses. MT and MT carried out the elemental analyses of the incinerated cellophane. VR contributed to the TG analyses. AF carried out the DLS experiments. RO measured the UV-Vis, CD and fluorescence spectra. TAY contributed to the theoretical analyses and wrote the manuscript. All authors discussed the results and commented on the manuscript.

Funding Open access funding provided by Università degli Studi di Napoli Federico II within the CRUI-CARE Agreement.

\section{Compliance with ethical standards}

Conflict of interest The authors declare no competing financial interest.

Open Access This article is licensed under a Creative Commons Attribution 4.0 International License, which permits use, sharing, 
adaptation, distribution and reproduction in any medium or format, as long as you give appropriate credit to the original author(s) and the source, provide a link to the Creative Commons licence, and indicate if changes were made. The images or other third party material in this article are included in the article's Creative Commons licence, unless indicated otherwise in a credit line to the material. If material is not included in the article's Creative Commons licence and your intended use is not permitted by statutory regulation or exceeds the permitted use, you will need to obtain permission directly from the copyright holder. To view a copy of this licence, visit http://creativecommons .org/licenses/by/4.0/.

\section{References}

1. Klemm D, Heublein B, Fink HP, Bohn A. Cellulose: fascinating biopolymer and sustainable raw material. Angew Chem Int Ed. 2005;44:3358-93.

2. Elia V, Oliva R, Napoli E, Germano R, Pinto G, Lista L, Niccoli M, Toso D, Vitiello G, Trifuoggi M, Giarra A, Yinnon TA. Experimental study of physicochemical changes in water by iterative contact with hydrophilic polymers: a comparison between Cellulose and Nafion. J Mol Liq. 2018;268:598-609.

3. Elia V, Marchettini N, Napoli E, Niccoli M. Calorimetric, conductometric and density measurements of iteratively filtered water using 450, 200, 100 and $25 \mathrm{~nm}$ Millipore filters. J Therm Anal Calorim. 2013;114:927-36.

4. Elia V, Ausanio G, De Ninno A, Germano R, Napoli E, Niccoli M. Experimental evidences of stable water nanostructures at standard pressure and temperature obtained by iterative filtration. Water. 2014;5:121-30.

5. Capolupo A, Del Giudice E, Elia V, Germano R, Napoli E, Niccoli M, Tedeschi A, Vitiello G. Self-similarity properties of Nafionized and filtered water and deformed coherent states. Int J Mod Phys B. 2014;28:1450007.

6. Zheng JM, Chin WC, Khijniak E, Khijniak E Jr, Pollack GH. Surfaces and interfacial water: evidence that hydrophilic surfaces have long-range impact. Adv Colloid Interface Sci. 2006;127:19-27.

7. Zheng JM, Pollack GH. Solute exclusion and potential distribution near hydrophilic surfaces. In: Pollack GH, Cameron IL, Wheatley DN, editors. Water and the cell. Dordrecht: Springer; 2006. p. 165-74.

8. Sulbarán B, Toriz G, Allan GG, Pollack GH, Delgado E. The dynamic development of exclusion zones on cellulosic surfaces. Cellulose. 2014;21:1143-8.

9. Segarra-Martí J, Coto PB, Rubio M, Roca-Sanjuán D, Merchán $M$. Towards the understanding at the molecular level of the structured-water absorption and fluorescence spectra: a fingerprint of $\pi$-stacked water. Mol Phys. 2013;111:1308-15.

10. Segarra-Martí J, Roca-Sanjuán D, Merchán M. Can the hexagonal ice-like model render the spectroscopic fingerprints of structured water? Feedback from quantum-chemical computations. Entropy. 2014;16:4101-20.

11. Elia V, Ausanio G, De Ninno A, Gentile F, Germano R, Napoli E, Niccoli M. Experimental evidence of stable aggregates of water at room temperature and normal pressure after iterative contact with a Nafion ${ }^{\circledR}$ polymer membrane. Water. 2013;5:16-26.

12. Elia V, Napoli E, Niccoli M. Physical-chemical study of water in contact with a hydrophilic polymer: Nafion. J Therm Anal Calorim. 2013;112:937-44.

13. Elia V, Lista L, Napoli E, Niccoli M. A thermodynamic characterization of aqueous nanostructures of water molecules formed by prolonged contact with the hydrophilic polymer Nafion. J Therm Anal Calorim. 2014;115:1841-9.

14. Elia V, Germano R, Napoli E. Permanent dissipative structures in water: the matrix of life? Experimental evidences and their quantum origin. Curr Top Med Chem. 2015;15:559-71.

15. Elia V, Yinnon TA, Oliva R, Napoli E, Germano R, Bobba F, Amoresano A. Chiral micron-sized $\mathrm{H}_{2} \mathrm{O}$ aggregates in water: circular dichroism of supramolecular $\mathrm{H}_{2} \mathrm{O}$ architectures created by perturbing pure water. Water. 2017;8:1-29.

16. Yinnon TA, Elia V, Napoli E, Germano R, Liu Z-Q. Water ordering induced by interfaces: an experimental and theoretical study. Water. 2016;7:96-128.

17. Bunkin NF, Ignatiev PS, Kozlov VA, Shkirin AV, Zakharov SD, Zinchenko AA. Study of the phase states of water close to Nafion interface. Water. 2013;4:129-54.

18. Zhang Y, Takizawa S, Lohwacharin J. Spontaneous particle separation and salt rejection by hydrophilic membranes. Water. 2015;7:1-18.

19. Elia V, Niccoli M. Thermodynamics of extremely diluted aqueous solutions. Ann N Y Acad Sci. 1999;879:241-8.

20. Elia V, Napoli E, Niccoli M. Calorimetric and conductometric titrations of nanostructures of water molecules in iteratively filtered water. J Therm Anal Calorim. 2013;111:815-21.

21. Elia V, Napoli E. Nanostructures of water molecules in iteratively filtered water. Key Eng Mater. 2011;495:37-40.

22. De Grotthuss CJT. Sur la décomposition de l'eau et des corps qu'elle tient en dissolution à l'aide de l'électricité galvanique. Ann Chim LVIII. 1806;58:54-74.

23. Agmon N. The Grotthuss mechanism. Chem Phys Lett. 1995;244:456-62.

24. Gilead E, Kirowa-Eisner E. Electrolytic conductivity-the hopping mechanism of the proton and beyond. Electrochim Acta. 2006;51:6003-11.

25. Laliberté M, Cooper WE. Model for calculating the density of aqueous electrolyte solutions. J Chem Eng Data. 2004;49:1141-51.

26. Chai B, Mahtani AG, Pollack GH. Unexpected presence of solute-free zones at metal-water interfaces. Contemp Mater. 2012;3:1-12.

27. Lunev IV, Khamzin AA, Popov II, Ovchinnikov MN, Ryzhkina IS, Mishina OM, Kiseleva YV, Konovalov AI. Dielectric spectroscopy study of low concentration aqueous solutions of a Calix[4]resorcinarene derivative. Dokl Phys Chem. 2014;455:56-9.

28. De Ninno A, De Francesco M. Water molecules ordering in strong electrolytes solutions. Chem Phys Lett. 2018;705:7-18.

29. Arani R, Bono I, Del Giudice E, Preparata G. QED coherence and the thermodynamics of water. Int J Mod Phys B. 1995;9:1813-41.

30. Bono I, Del Giudice E, Gamberale L, Henry M. Emergence of the coherent structure of liquid water. Water. 2012;4:510-32.

31. Del Giudice E, Tedeschi A, Vitiello G, Voeikov V. Coherent structures in liquid water close to hydrophilic surfaces. J Phys: Conf Ser. 2013;442:012028.

32. De Ninno A. Dynamics of formation of the exclusion zone near hydrophilic surfaces. Chem Phys Lett. 2017;667:322-6.

33. Sivasubramanian S, Widom A, Srivastava YN. The Clausius-Mossotti phase transition in polar liquids. Phys A. 2005;345:356-66.

34. Del Giudice E, Preparata G, Vitiello G. Water as a free electric dipole laser. Phys Rev Lett. 1988;61:1085-8.

35. Del Giudice E, Vitiello G. Role of the electromagnetic field in the formation of domains in the process of symmetry-breaking phase transitions. Phys Rev A. 2006;74:022105-1-9.

36. Liu X, Yu W. Evaluating the thermal stability of high performance fibers by TGA. Appl Polym. 2006;99:937-44.

37. Elia V, Napoli E, Germano G, Oliva R, Roviello V, Niccoli M, Amoresano A, Naviglio D, Ciaravolo M, Trifuoggi M, Yinnon TA. New chemical-physical properties of water after iterative 
procedure using hydrophilic polymers: the case of paper filter. $\mathbf{J}$ Mol Liq. 2019;296:111808.

38. Accardo A, Tesauro D, Morelli G, Gianolio E, Aime S, Vaccaro M, Mangiapia G, Paduano L, Schillen K. High-relaxivity supramolecular aggregates containing peptides and Gd complexes as contrast agents in MRI. J Biol Inorg Chem. 2007;12:267-76.

39. Vergara A, Paduano L, Sartorio R. Mechanism of proteinpoly(ethylene glycol) interaction from a diffusive point of view. Macromolecules. 2002;35:1389-98.

40. Lakowicz JR. Principles of fluorescence spectroscopy. New York: Springer; 2006.

41. Litjens RAJ, Quickenden TI, Freeman CG. Visible and nearultraviolet absorption spectrum of liquid water. Appl Opt. 1999;38:1216-23.

42. Chai B-H, Zheng J-M, Zhao Q, Pollack GH. Spectroscopic studies of solutes in aqueous solution. J Phys Chem A. 2008;112:2242-7.

43. Lo S-Y. Anomalous state of ice. Mod Phys Lett. 1996;10:909-19.

44. Quickenden TI, Irvin JA. The ultraviolet absorption spectrum of liquid water. J Chem Phys. 1980;72:4416-28.

45. Cabral do Couto P, Chipman DM. Insights into the ultraviolet spectrum of liquid water from model calculations: the different roles of donor and acceptor hydrogen bonds in water pentamers. J Chem Phys. 2012;137:18430.
46. Fasman GD, editor. Circular dichroism and the conformational analysis of biomolecules. New York: Springer; 1996.

47. Ernst KH. Molecular chirality at surfaces. Phys Status Solidi B. 2012;249:2057-88

48. McDermott ML, Vanselous H, Corcelli SA, Petersen PB. DNA's chiral spine of hydration. ACS Cent Sci. 2017;3:708-14.

49. Elia V, Yinnon TA, Oliva R, Napoli R, Germano R, Bobba F, Amoresano A. DNA and the chiral water superstructure. J Mol Liq. 2017;248:1028-9.

50. Valeur B. Molecular fluorescence: principles and applications. Weinheim: Wiley; 2001.

51. Belovolova LV, Glushkov MV, Vinogradov EA, Babintsev VA, Golovanov VI. Ultraviolet fluorescence of water and highly diluted aqueous media. Phys Wave Phenom. 2009;17:21-31.

Publisher's Note Springer Nature remains neutral with regard to jurisdictional claims in published maps and institutional affiliations. 